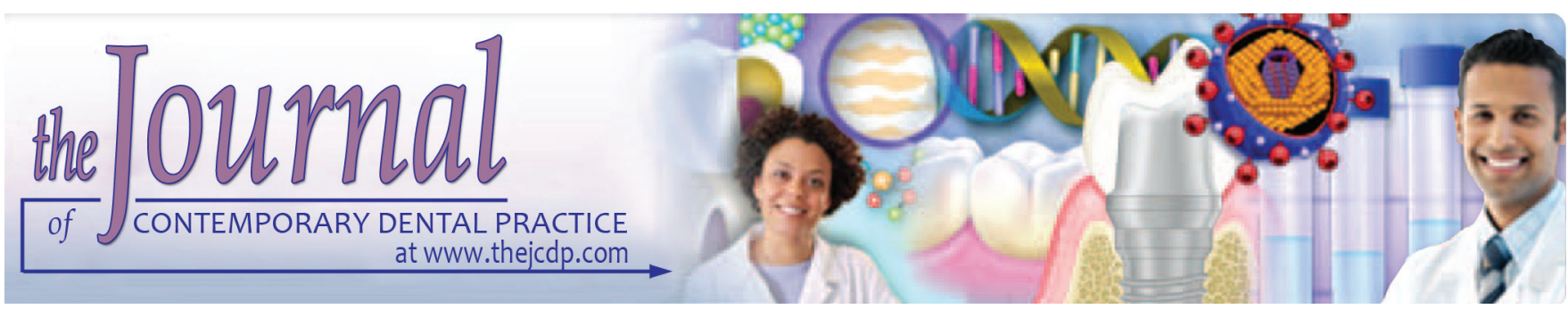

\title{
Comparison of Preoperative and Perioperative Antibiotic Prophylaxis Regimen in Compound Facial Fractures
}

\author{
${ }^{1}$ Veeranjaneyalu Mamthashri, ${ }^{2}$ Bokka Praveen Reddy
}

\begin{abstract}
Aims and objectives: Intraoperative antibiotics may be effective in elective surgery; there may be an advantage to starting antibiotics preoperatively when there is already an infective focus, such as compound facial fractures. The purpose of this study is to compare preoperative and intraoperative antibiotic prophylaxis in compound facial fractures.

Materials and methods: This is a prospective study conducted over a period of 2 years on 50 patients, who underwent open reduction and rigid internal fixation. The patients were assigned to two groups. The patients in group I received antibiotics at the time of admission. The patients in group II received antibiotics perioperatively at the time of induction of general anesthesia. Postoperatively, the patients were evaluated for the reduction of pain and the presence of infection by assessing the local presence of erythema, swelling, a rise in temperature, and purulent discharge, if any, on a predefined proforma.
\end{abstract}

Results: A total of 72 fractures were assessed in 50 patients. There was an overall reduction of pain in both the groups. Wound healing status was found to be satisfactory in both the groups.

Conclusion: Wound status and infection rate were evaluated in patients of both the groups. In the study, there was no difference between the two groups on the predecided parameters whether the antibiotics were given either preoperatively or perioperatively.

Clinical significance: It is very essential to have a sound knowledge of the use of antibiotic therapy effectively to prevent the overuse of it and, thereby, help avoid developing resistance to antibiotics in patients.

1Department of Oral and Maxillofacial Surgery, Government Dental College and Research Institute, Bengaluru, Karnataka, India

${ }^{2}$ Department of Oral and Maxillofacial Surgery, Dental College Regional Institute of Medical Sciences, Imphal, Manipur, India

Corresponding Author: Veeranjaneyalu Mamthashri Department of Oral and Maxillofacial Surgery, Government Dental College and Research Institute, Bengaluru, Karnataka, India Phone: +919972888088, e-mail: mamthashri15@gmail.com
Keywords: Antibiotics, Facial fractures, Infection, Intraoperative, Perioperative.

How to cite this article: Mamthashri V, Reddy BP. Comparison of Preoperative and Perioperative Antibiotic Prophylaxis Regimen in Compound Facial Fractures. J Contemp Dent Pract 2018;19(2):214-220.

Source of support: Nil

Conflict of interest: None

\section{INTRODUCTION}

The motto "prevention is better than cure" is apt when discussing prophylactic antibiotics, as it is presumed to be beneficial in the prevention of wound infection. The benefits of antibiotic prophylaxis have been demonstrated using animal models as well as clinical studies, and a number of authors have advocated the use of prophylactic antibiotics. $^{1-3}$

The purpose of this study was to evaluate the role and significance of preoperative and perioperative antibiotic prophylaxis for patients undergoing surgical management of compound facial fractures.

The objective of this study was to determine the timing of the first dose of prophylactic antibiotics. The aim of the study was to evaluate the role of preoperative and perioperative antibiotic prophylaxis in patients with compound facial fractures undergoing surgical treatment of open reduction and rigid internal fixation.

The goals of prophylactic antibiotic to surgical patients with compound facial fracture were to reduce the incidence of surgical wound infection, to use antibiotics in a manner that is supported by evidence of effectiveness, and to minimize the adverse effects of antibiotics.

\section{MATERIALS AND METHODS}

A total of 50 patients between the ages of 14 years and 60 years diagnosed with compound facial fractures on 
clinical and radiological assessments and requiring treatment were included in this study.

The study was conducted on an inpatient basis, between November 2004 and June 2006, in the Department of Oral and Maxillofacial Surgery, College of Dental Sciences, Davangere, Karnataka, India.

The following were the inclusion and exclusion criteria for selecting the patients.

\section{Inclusion Criteria}

- Patients willing to consent to be a participant in the study.

- Patients with compound facial fractures requiring surgical intervention by open reduction and rigid internal fixation.

- Routine blood and urine examination values being within normal parameters.

- Patient being available for the entire period of assessment.

\section{Exclusion Criteria}

- Patients who refused to consent to the procedure.

- Patients who failed to return for postoperative visits.

- Immunocompromised patients and patients with systemic conditions, such as pregnancy, diabetes mellitus, cardiovascular disease, and bleeding disorders.

- Complex and comminuted fractures.

- Patients who were already on antibiotics or those who were allergic to penicillin.

A prestructured proforma was used to collect information regarding patient's history, history of trauma, and other relevant information. A chest radiograph, an electrocardiogram, and physician's consent were obtained as a part of the preoperative assessment. After obtaining consent for the study, each patient was randomly assigned into one of the two treatment groups (Groups I and II), using prepared randomization in sealed envelopes.

\section{Group I}

This group consisted of 25 patients. These patients received a prophylactic antibiotic dose of $1 \mathrm{gm}$ of amoxicillin and cloxacillin combination in equal doses, every 8th hour and $400 \mathrm{mg}$ metronidazole intravenously, every 8th hour, at the time of admission.

Postoperatively, the patients received $500 \mathrm{mg}$ of amoxicillin and cloxacillin combination in equal doses and $400 \mathrm{mg}$ of metronidazole, orally from the 2nd postoperative day until the 5 th postoperative day, excluding the preoperative dose.

\section{Group II}

This group consisted of 25 patients. These patients received a prophylactic dose of $1 \mathrm{gm}$ amoxicillin and cloxacillin combination in equal doses and $500 \mathrm{mg}$ metronidazole, intravenously, on the operative day, before surgery, and at the time of induction of general anesthesia.

The patients in this group received a therapeutic dose of $500 \mathrm{mg}$ of amoxicillin and cloxacillin combination and $400 \mathrm{mg}$ of metronidazole orally, from 2 nd postoperative day until the 5 th postoperative day.

All patients were given analgesics to be taken as required for pain relief. The patients were instructed not to take any drugs other than those prescribed and not to seek medical help elsewhere for postoperative problems.

\section{Surgical Procedures}

An informed consent was taken from all the patients individually before the procedure. Patients were administered general anesthesia following nasal intubation. Local anesthetic ( $2 \%$ lignocaine hydrochloride with 1:80,000 adrenaline) was injected in and around the surgical site for hemostasis. A combination of transoral vestibular incisions and facial incisions were used. In some cases, a combination of both transoral and facial incisions were used. A subperiosteal dissection was carried out to expose the bone and the fractured fragments.

After exposing the fractured fragments, the site was debrided thoroughly, curetted, and irrigated copiously with normal saline. The fracture fragments were reduced and fixed with miniplates and screws. Selection of plates varied from patient-to-patient depending on the anatomical site and complexity of the fracture. After achieving hemostasis, the wound was closed in layers. The subcutaneous layer was closed with 3-0 resorbable sutures, and skin or mucosal tissue was closed with 3-0 black braided silk or polypropylene using interrupted sutures. After the wound closure, pressure dressing was applied over the operated site. The patients were extubated and sent for recovery and wards where the follow-up was done.

\section{RESULTS}

Patients with abscess or infected fractures preoperatively, those who had received prophylactic antibiotics 1 week before the admission, and fractures older than 36 hours were excluded from the study. The parameters included were age, sex, site of fracture, the duration of surgery, duration between injury and treatment, various surgical approaches, postoperative assessment of pain, presence of infection by evaluating for the presence of erythema, a rise in temperature, purulent discharge, and swelling around the wound; and wound status. Patients were assessed on 1st, 2nd, 3rd, and 5th week postoperatively. 
Patients were evaluated for the incidence of pain, infection, and wound status.

Table 1 and Graph 1 shows the descriptive statistics of sex in both the groups. Considering the patients from the two groups, there were 24 males and 1 female in group I and 21 males and 4 females in group II; $p=0.16$ using chi-squared test showed no significant difference in sex ratio in both the groups. The age range in groups I and II is shown in Table 2 and Graph 2. The age range in group I was 16 to 40 years with a mean age of 27.9, and showed no significant difference in the age in both the groups. The distribution of fracture in both the groups is shown in Table 3 and Graph 3. There were a total of 72 facial fractures seen in 50 patients in both the groups in this study. Among the 72 facial fractures, 14 were midfacial fractures and 58 were mandibular fractures. Group I patients had a total of 35 facial fractures

Table 1: Sex-wise distribution of patients

\begin{tabular}{|c|c|c|c|c|c|c|}
\hline \multirow[b]{2}{*}{ Sex } & \multicolumn{2}{|c|}{$\begin{array}{c}\text { Group I } \\
n=25\end{array}$} & \multicolumn{2}{|c|}{$\begin{array}{c}\text { Group II } \\
n=25\end{array}$} & \multirow[b]{2}{*}{$\chi^{2}$} & \multirow[b]{2}{*}{$p$-value * } \\
\hline & $n$ & $\%$ & $n$ & $\%$ & & \\
\hline Male & 24 & 96 & 21 & 84 & \multirow{2}{*}{2.0} & \multirow{2}{*}{$0.16, \mathrm{NS}$} \\
\hline Female & 1 & 4 & 4 & 16 & & \\
\hline
\end{tabular}

${ }^{*}$ Chi-square test, NS: Not significant

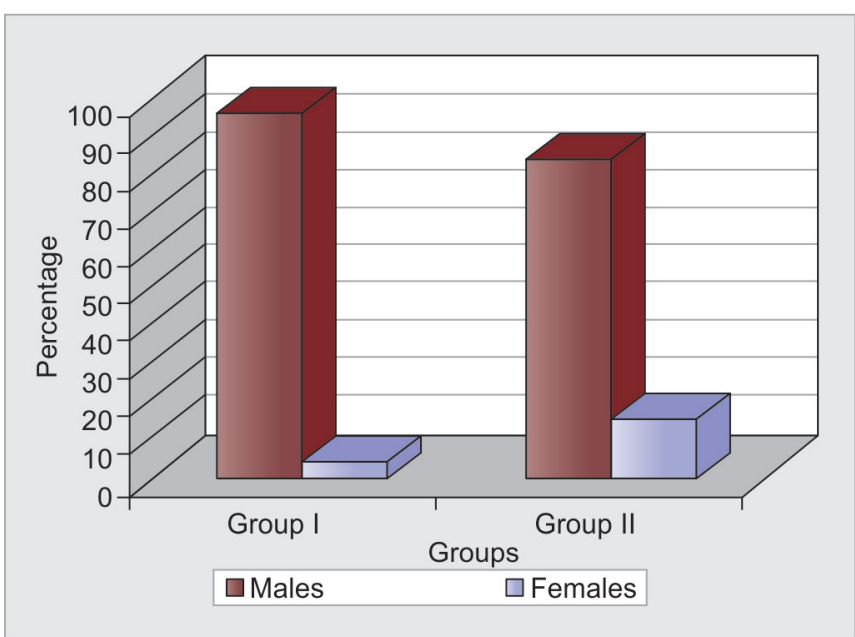

Graph 1: Sex-wise distribution of patients in both the groups

Table 2: Age wise distribution of patients

\begin{tabular}{lcccccc}
\hline & \multicolumn{2}{c}{$\begin{array}{c}\text { Group I } \\
\text { Age (years) }\end{array}$} & & \multicolumn{2}{c}{ Group II } \\
Range & $n$ & $\%$ & & $n$ & $\%$ & p-value* \\
\cline { 2 - 3 } \cline { 5 - 6 }$n$ & 2 & 8 & & 5 & 20 & $0.19, \mathrm{NS}$ \\
$21-20$ & 13 & 52 & & 9 & 36 & \\
$31-40$ & 10 & 40 & & 7 & 28 & \\
$41-50$ & - & - & & 3 & 12 & \\
$51-60$ & - & - & & 1 & 4 & \\
Mean \pm SD & $27.9 \pm 5.7$ & & $31.2 \pm 11.0$ & \\
\hline
\end{tabular}

*Student 't' test, $\mathrm{t}=1.34, \mathrm{NS}$ : Not significant and Group II patients had 37 facial fractures; $p=0.28$ using chi-squared test showed no significant difference in the site of fractures in both the groups as shown in Table 4 and Graph 4. There was no significant difference in both the groups in terms of age, sex, or site of fracture location, who were selected for the study. The time interval between injury and surgery was almost of the same range for both the groups of patients (Table 5 and Graph 5). Duration of surgery was also almost of the same range for patients of both groups. Our study demonstrated no significant difference among the two groups in terms of pain experience (Table 6 and Graph 6), the presence of erythema, and presence of swelling, temperature (Table 7 and Graph 7), and wound status (Table 8 and Graph 8).

There was no significant difference in both the groups in the rate of infection.

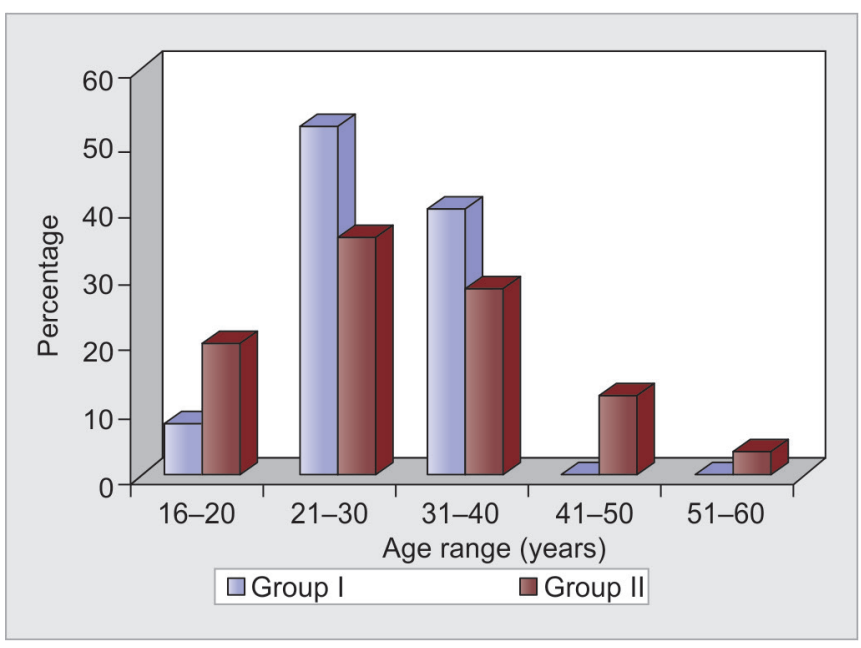

Graph 2: Age wise distribution of patients in both the groups

Table 3: Distribution of facial fractures

\begin{tabular}{llll}
\hline Site of fractures & Group I $n(\%)$ & Group II $n(\%)$ & $p$-value* \\
\hline Facial & $5(14.3)$ & $9(24.3)$ & $0.28, \mathrm{NS}$ \\
Mandible & $30(85.7)$ & $28(75.7)$ & \\
\hline
\end{tabular}

${ }^{*}$ Chi-square test, $\chi^{2}=1.16$, NS: Not significant

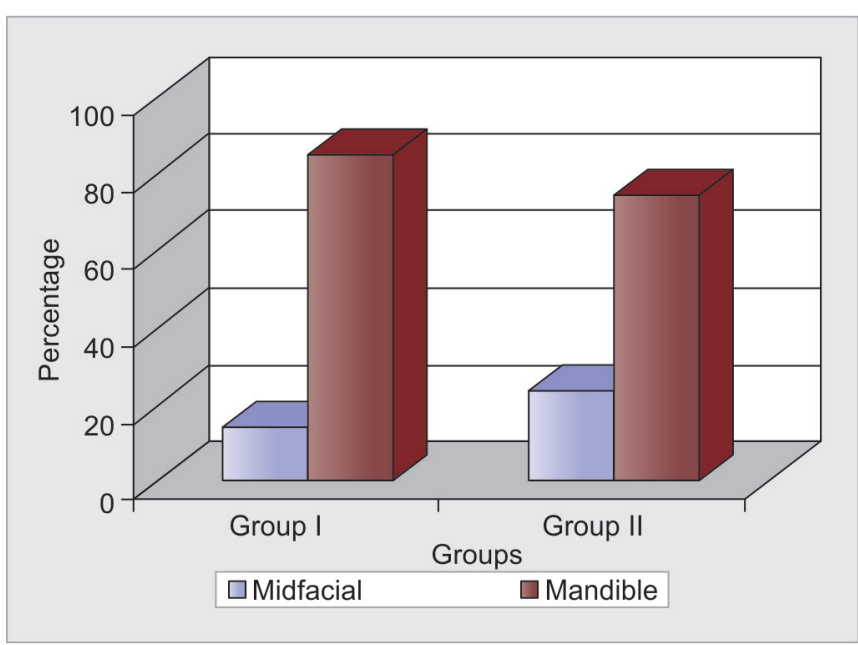

Graph 3: Distribution of facial fractures in both the groups 
Table 4: Descriptive statistics on the site of fractures in group I and group II

\begin{tabular}{llll}
\hline Site of fractures & Group I $n(\%)$ & Group II $n(\%)$ & $p$-value \\
\hline Parasymphysis & $10(28.6)$ & $15(40.5)$ & $0.23, \mathrm{NS}$ \\
Angle & $6(17.1)$ & $4(10.8)$ & $0.34, \mathrm{NS}$ \\
Subcondylar & $6(17.1)$ & $4(10.8)$ & $0.34, \mathrm{NS}$ \\
Body & $6(17.1)$ & $3(8.1)$ & $0.19, \mathrm{NS}$ \\
Symphysis & $2(5.7)$ & $2(5.4)$ & $0.67, \mathrm{NS}$ \\
Lefort & $1(2.9)$ & $1(2.7)$ & $0.61, \mathrm{NS}$ \\
Zygomatico- & $4(11.4)$ & $8(21.6)$ & $0.22, \mathrm{NS}$ \\
maxillary complex & & & \\
\hline Total & 35 & 37 & - \\
\hline
\end{tabular}

NS: Not significant

Table 5: Mean interval between injury and surgery (in days)

\begin{tabular}{llll}
\hline $\begin{array}{l}\text { Time interval } \\
\text { (days) }\end{array}$ & $\begin{array}{l}\text { Group I }(n=25) \\
n(\%)\end{array}$ & $\begin{array}{l}\text { Group II }(n=25) \\
n(\%)\end{array}$ & \begin{tabular}{l} 
p-value* \\
\hline 1
\end{tabular} \\
2 & $10(40)$ & $5(20)$ & 0.10, NS \\
2 & $6(24)$ & \\
3 & $10(40)$ & $12(48)$ & \\
4 & $5(20)$ & $2(8)$ & \\
Mean (SD) & $2.8(0.8)$ & $2.4(0.9)$ & \\
Range & $2-4$ & $1-4$ & \\
\hline
\end{tabular}

*Student ' $\mathrm{t}$ ' test, $\mathrm{t}=1.70, \mathrm{NS}$ : Not significant

Table 6: Incidence of postoperative pain in group I and group II

\begin{tabular}{|c|c|c|c|c|c|c|}
\hline $\begin{array}{l}\text { Time of } \\
\text { assessment } \\
\text { (in weeks) }\end{array}$ & Groups & $\begin{array}{l}\text { Normal } \\
n(\%)\end{array}$ & $\begin{array}{l}\text { Mild } \\
n(\%)\end{array}$ & $\begin{array}{l}\text { Moderate } \\
n(\%)\end{array}$ & $\begin{array}{l}\text { Severe } \\
n(\%)\end{array}$ & $p$-value * \\
\hline \multirow[t]{2}{*}{ 1st } & I & - & $15(60)$ & $9(36)$ & $1(4)$ & $0.52, \mathrm{NS}$ \\
\hline & II & $2(8)$ & $15(60)$ & $7(28)$ & $1(4)$ & \\
\hline \multirow[t]{2}{*}{ 2nd } & I & $8(32)$ & $10(40)$ & $7(28)$ & - & $0.54, \mathrm{NS}$ \\
\hline & II & $9(36)$ & $13(52)$ & $3(12)$ & - & \\
\hline \multirow[t]{2}{*}{ 3rd } & I & $16(64)$ & $9(36)$ & - & - & 0.77, NS \\
\hline & II & $17(68)$ & $8(32)$ & - & - & \\
\hline \multirow[t]{2}{*}{ 5th } & I & $23(92)$ & $2(8)$ & - & - & $0.51, \mathrm{NS}$ \\
\hline & II & $23(92)$ & $1(4)$ & $1(4)$ & - & \\
\hline
\end{tabular}

${ }^{*}$ Fischer's exact test, NS: Not significant

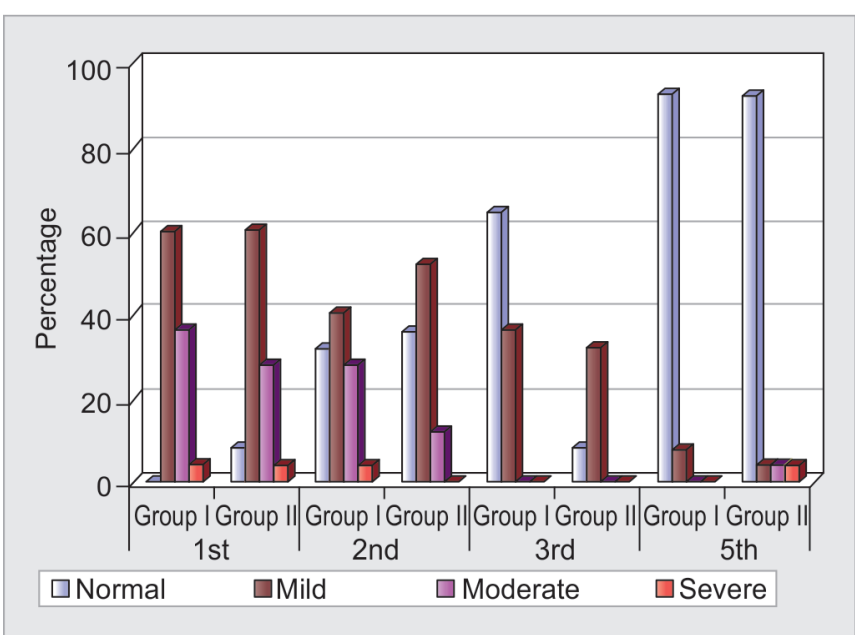

Graph 6: Incidence of postoperative pain

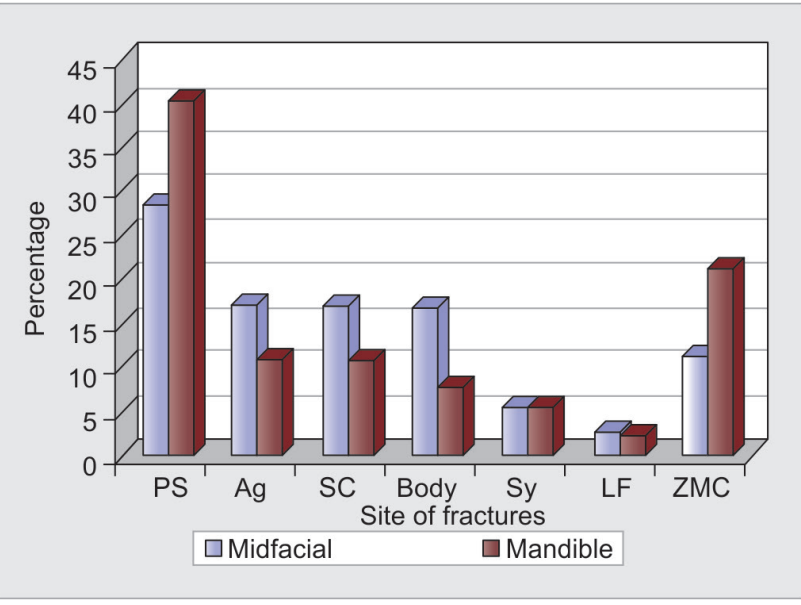

Graph 4: Distribution of the individual fracture site: PS: Parasymphysis; Ag: Angle; SC: Subcondylar; Sy: Symphysis; LF: Lefort; ZMC: Zygomatico-maxillary complex

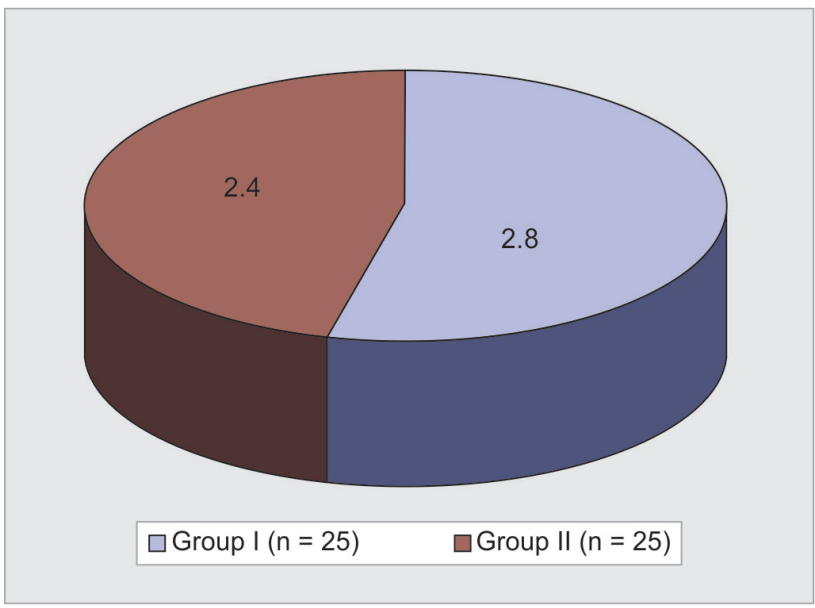

Graph 5: Mean interval between injury and surgery (in days)

Table 7: Postoperative temperature

\begin{tabular}{lll}
\hline $\begin{array}{l}\text { Time interval } \\
\text { (in weeks) }\end{array}$ & $\begin{array}{l}\text { Group I }\left(\text { Temp- }^{\circ} \mathrm{F}\right) \\
\text { Mean }(S D)\end{array}$ & $\begin{array}{l}\text { Group II (Temp- } \\
\text { Mean }(S D)\end{array}$ \\
\hline 1st & $98.7(0.4)$ & $98.7(0.5)$ \\
2nd & $98.8(0.4)$ & $98.4(0.7)$ \\
3rd & $97.8(0.9)$ & $97.9(0.9)$ \\
5th & $97.4(0.9)$ & $97.8(0.9)$ \\
\hline
\end{tabular}

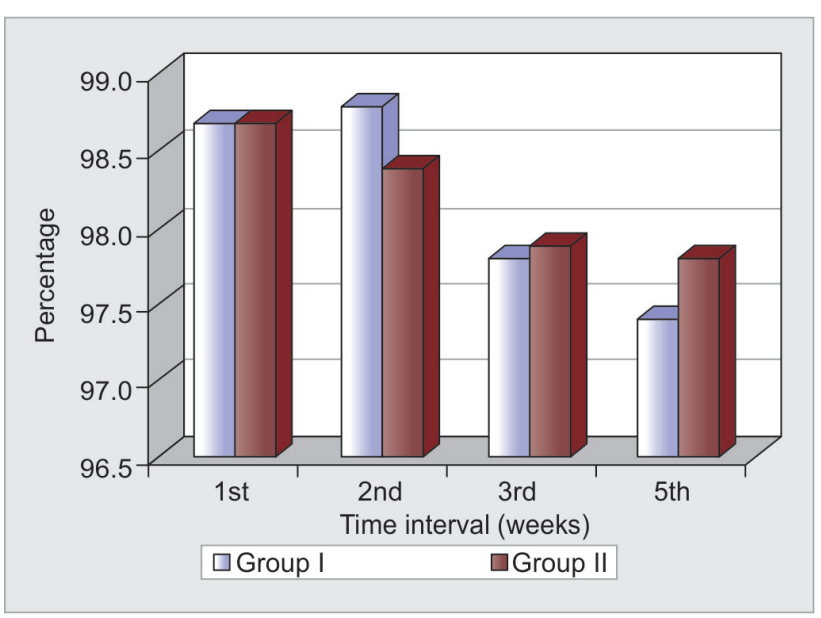

Graph 7: Incidence of postoperative temperature 
Table 8: Wound status in groups I and II

\begin{tabular}{lllllll}
\hline & Wound & 1st & 2nd & 3rd & 5th & \\
Groups status & week & week & week & week & p-value \\
\hline I & Infected & $1(4)$ & 0 & 0 & 0 & 1.00, \\
& Satisfactory $24(96)$ & $25(100)$ & $25(100)$ & $25(100)$ & NS \\
II & Infected & 0 & 0 & 0 & $1(4)$ & \\
& Satisfactory $25(100)$ & $25(100)$ & $25(100)$ & $24(96)$ \\
\hline
\end{tabular}

*Fischer's exact test, NS: Not significant

\section{DISCUSSION}

The use of perioperative antibiotics to prevent infection postoperatively has been established in part, by the work of Zallen and Curry. This study examined both open and closed methods of treatments, but the antibiotic choice, timing, and duration of administration were not part of the study protocol. ${ }^{4}$

There was no significant difference in terms of age and sex in both the groups. All patients had only facial fractures with no other associated fractures of the body. Mandibular fractures were more commonly encountered than midfacial fractures in both the groups. Among the mandibular fractures, the highest number of fractures was seen in the parasymphysis (PS) region in group I, followed by angle, subcondylar, and body fractures. In group II, the highest numbers of fractures were seen in the PS region followed by the zygomatico-maxillary region.

Studies have shown that antibiotic prophylaxis is indicated for laceration wounds that are extensive, visibly clean, and treated within 3 hours of injury. Prophylactic antibiotic should be started immediately and continued until definitive treatment is carried out usually within 24 hours when a delay in treatment is expected. ${ }^{2,5}$ The prophylactic use of antibiotics within 3 hours after injury might be effective in preventing infection. ${ }^{3}$ Compound facial bone fractures seen after 3 hours of the injury (wounds that are visibly contaminated) should be assumed to be infected, and antibiotic should be prescribed as for an established infection. 3,6,7

In our study, patients in group I received prophylactic antibiotics intravenously at the time of admission. However, the time lapse from injury to the presentation of almost all the patients in both the groups was more than 3 hours.

Postoperative wound infection rate is related to the class of surgery where patients with fresh compound facial fractures belonged to class 3 surgery (contaminated surgery), and patients with compound facial bone fractures and orofacial lacerations seen and treated late belonged to class 4 surgery (dirty infected surgery) and had an infection rate of 25 to $50 \%$. In class 3 surgeries, if the duration of surgery is more than $120 \mathrm{~min}$ in patients with American Society of Anesthesiologists (ASA) score more than 2 , then the infection rate was $65 \% .8,9$

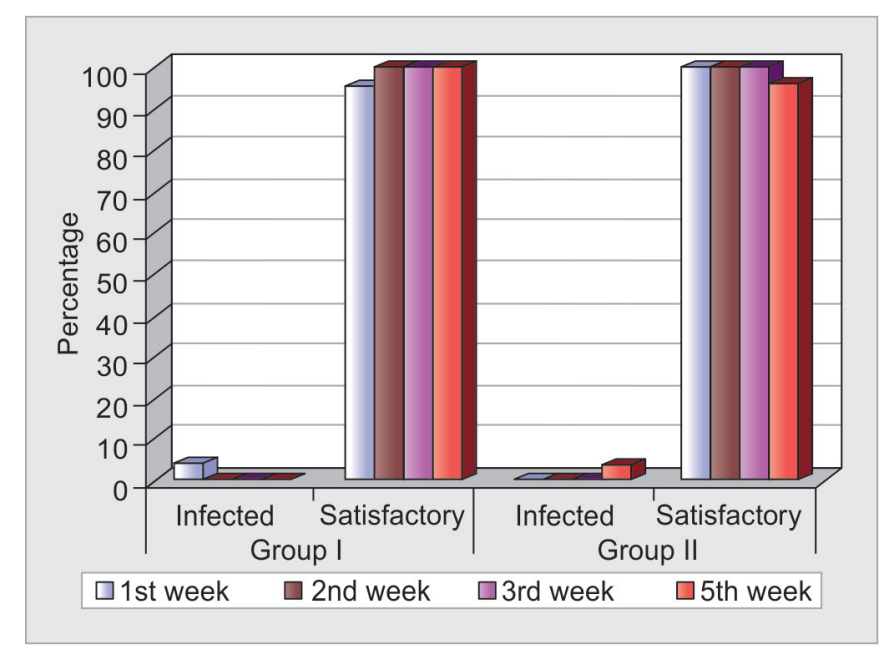

Graph 8: Postoperative wound status in both the groups

The patients selected in our study were limited to ASA score $<2$, with a mean duration of surgery of 123.8 minutes and had a mean (time interval between the time of admission) preoperative stay of 2.6 days. The infection rate in both the groups was $8 \%$.

In our study, we used a combination of amoxicillin and cloxacillin, as they were effective against both streptococci and staphylococci, which are commonly encountered during intraoral and extraoral surgeries respectively. This combination was preferred due to its narrow spectrum of antimicrobial activity compared with the other broad-spectrum cephalosporin, but broader than that of penicillin $\mathrm{G}$ and V. Amoxicillin is more effective against streptococci than the cephalosporins. ${ }^{10}$

As metronidazole is a bactericidal antibiotic, which is very effective against dental infections caused by anaerobes, ${ }^{11,12}$ it was included in both our study groups.

It has been shown that peak plasma concentrations of antibiotics are achieved more quickly after rapid intravenous (IV) administration than continuous IV infusion or intramuscular injections. We have used the IV route for administration of antibiotics in our patients, preoperatively or perioperatively. The peak therapeutic concentration of an antibiotic at the site of potential infection should be 3 to 4 times the minimum inhibitory concentration. ${ }^{13}$ The first dose of prophylactic antibiotics is, therefore, at least twice the therapeutic dose. ${ }^{1,2,14}$ Subsequent doses, which are given if the surgery is prolonged, should be at a usual therapeutic dose as recommended by the British Society for Antimicrobial Chemotherapy. ${ }^{14}$

The main aim of timing in antibiotic prophylaxis is to reduce surgical wound infection. There are a number of studies done to know the occurrence of surgical wound infection in relation to the timing of antibiotic prophylaxis.

Many prospective trials have shown that the lowest rate of surgical wound infection was associated when 
antibiotic was used within a 2-hour period before placement of an incision, as compared with 2 to 24 hours before the incision. ${ }^{6,15}$

In our study, patients in group I received prophylactic antibiotics of $1 \mathrm{gm}$ of amoxicillin and cloxacillin combination preoperatively at the time of admission every 6 th hour. The infection seen in this group was $4 \%$. Patients in group II received $1 \mathrm{gm}$ of amoxicillin and cloxacillin and $500 \mathrm{mg}$ metronidazole, perioperatively, at the time of induction of general anesthesia, by the IV route. We found that 1 (4\%) out of 25 patients in group II became infected. We also found the site of infection similar to the above study. No infection occurred in the midfacial fractures. For the mandibular fractures, no infection occurred in the subcondylar area. Infections occurred in the region of angle fractures in both the groups. This finding was consistent with that of the study conducted by Abubaker and Rollert. ${ }^{16}$ They found that most of the infections occurred in the angle or symphysis region. Statistically, it was not significant, and there was no difference in the incidence of infection in both the groups. We found that there was no added advantage of starting prophylactic antibiotics preoperatively in patients with compound facial fractures.

Hang and Assael ${ }^{17}$ suggest the use of perioperative, IV antibiotics for mandibular and maxillary fractures. The recommended antibiotic is aqueous penicillin of 1 to $1.5 \mathrm{gm}$ in adults, prophylactically. Postoperatively, the antibiotics can be given in the therapeutic dose of $500 \mathrm{mg}$ every 6 hours. According to Burke, ${ }^{18}$ prophylactic antibiotic should be repeated every 3 hours during the operation. Prophylactic dosage interval of antibiotics is approximately one-half the usual therapeutic intervals. Hence, when surgery is prolonged for more than 3 hours, subsequent intraoperative doses are required. ${ }^{1,19}$

For effective antimicrobial prophylaxis, adequate concentrations of the antibiotics must be present in the tissues at the onset and throughout the operative procedures. ${ }^{1,15,19-21}$ In our study, subsequent intraoperative antibiotics in therapeutic doses were given, intravenously, to patients of both the groups, if the surgery was for more than 3 hours. In the present prospective study of compound facial fractures, we continued antibiotics until the 5 th postoperative day, as for an established infection in both the groups.

If a fracture is already contaminated before the surgical procedure, then the term "prophylactic antibiotics" may not be appropriate in this situation. ${ }^{22,23}$ The fractured segments are contaminated at the time of the fracture and as well as at the time of surgery in compound facial fractures, especially, mandibular fractures involving the tooth-bearing segments. Hence, to prevent infection in a contaminated wound, the use of preoperative, perioperative, or postoperative antibiotics when dealing with these injuries is intended. However, a fracture site which is already infected by showing evidence of ongoing infection, such as erythema, purulence, osteolysis, fistulae, both clinically and radiographically is considered as a contaminated wound. In these situations, the necessity of preoperative, perioperative, and postoperative antibiotics is obvious. However, infected fractures at the time of admission were excluded from our study. In our study, infections were seen mostly in the mandibular angle region. In the subgroup of the zygoma and maxillary fractures, there were no infections. For mandibular fractures, no infection occurred in the subcondylar area. Almost all the infections observed in our study occurred in mandibular fractures and in those sites that produce compound fractures, which are either open to the mouth or have teeth in the line of fracture. It was seen that infection occurred in male patients in both the groups. One patient in the preoperative group had suture abscess on the 1st week. The suture was removed and the infection resolved with oral antibiotic therapy given for 5 days. One patient in the perioperative group had a periodontal abscess on the 5th week. Infected patient in group II had a mandibular 3rd molar in the line of fracture, which was a source of infection. Extraction of the 3rd molar was done; only one patient in the intraoperative group who developed an infection in the angle region had teeth (3rd molar) in the line of fracture, which was subsequently removed along with incision and drainage. There were many patients in both the groups who had teeth in the line of fracture, but did not develop any infection. The infected surgical site was successfully treated with incision and drainage, which was done extraorally, and the area was irrigated and sutured. The infected patients received $500 \mathrm{mg}$ of a combination of amoxicillin and cloxacillin orally, for 5 days after treatment. None of the infected patients required hospitalization or hardware removal.

The average delay of treatment from the time of injury in noninfected patients was 2.6 days in both the groups. In group $\mathrm{I}$, the time interval between injury and surgery was 2 to 4 days with a mean of 2.8 days. In group II, the time interval was 1 to 4 days with a mean of 2.4 days. The delay of treatment in infected patients in group I was 3 days, and in group II was 2 days from injury.

Furthermore, there was no untoward reaction or any adverse effects of antibiotics seen in patients of both the groups, in our study.

\section{CONCLUSION}

The main aim of prophylactic antibiotic is to prevent or decrease surgical wound infection, and prophylactic antibiotics are definitely indicated in fractures by many 
authors. Our study could not demonstrate any advantage of starting prophylactic antibiotics preoperatively at the time of admission in patients with compound facial fractures. It is, therefore, beneficial to start prophylactic antibiotics intravenously in a large bolus dose perioperatively at the time of induction of general anesthesia.

Probably stringent perioperative asepsis and thorough debridement of the wound with good postoperative wound management are more important for an uneventful healing. However, as is often noted, patients do not follow the postoperative instructions given, and to overcome this, many a times, it becomes necessary to prescribe routine prophylactic antibiotics following an injury and protracted surgical procedure where there is increase in chances of contamination and excessive instrumentation.

It is a well-known fact that surgical antibiotic prophylaxis is an adjunct to and is never a substitute for a good surgical technique. However, the decisions to adopt any recommendation must be at the surgeon's discretion made in the light of available evidence, resources, and circumstances presented by an individual patient.

\section{REFERENCES}

1. Peterson LJ. Antibiotic prophylaxis against wound infections in oral and maxillofacial surgery. J Oral Maxillofac Surg 1999 Jun;48(6):617-620.

2. Worthington, P.; Evans, JR.; editors. Controversies in oral and maxillofacial surgery. Philadelphia (PA): WB Saunders; 1993. pp. 95-100.

3. Herzon FS. The prophylactic use of antibiotics in head and neck surgery. Otoloryngol Clin North Am 1976 Oct;9(3):781-787.

4. Zallen RD, Curry JT. A study of antibiotic usage in compound mandibular fracture. J Oral Surg 1975;33:431-434.

5. Dellinger EP. Antibiotic prophylaxis in trauma: penetrating abdominal injuries and open fractures. Rev Infect Dis 1991 Sep-Oct;13(Suppl 10):S847-S857.

6. Classen DC, Evans RS, Pestotnik SL, Horn SD, Menlove RL, Burke JP. The timing of prophylactic administration of antibiotics and the risk of surgical wound infection. N Engl J Med 1992 Jan;326(5):281-286.

7. Muller, C.; Gadre, A. Principles of wound management. In: Rob and Smith operative surgery. 4th ed. Philadelphia (PA): Butterworth-Heinemann; 1986. pp. 608-623.
8. Garibaldi RA, Cushing D, Lerer T. Risk factors for postoperative infections. Am J Med 1991 Sep;91(3B):158S-163S.

9. Culver DH. National nasocomial infections surveillance system: surgical wound infection rates by wound class operative procedure and patient risk index. Am J Med 1991;91:152S-157S.

10. Alexander JS, Skyes NS, Mitchell MM, Fisher NW. The concentration of selected intravenously administered antibiotics in experimental surgical wounds. Ann Surg 1979;12:246.

11. Shore KP, Pottumarthy S, Morris AJ. Susceptibility of anaerobic bacteria in Auckland. N Z Med J 1999 Dec;112:424-426.

12. Ingham HR, Hood FJ, Bradnum $P$, Tharagonnet $D$, Selkon JB. Metronidazole compared with penicillin in the treatment of acute dental infections. Br J Oral Surg 1977 Mar;14(3):264-269.

13. Norris LH, Doku HC. Antimicrobial prophylaxis in oral surgery. Oral and Maxillofac Surg Infect 1992 Sep;2:85-92.

14. British Society for Antimicrobial Chemotherapy Endocarditic Working Party. Antibiotic prophylaxis of infective endocarditis. Lancet 1992;339:1292-1293.

15. Greenberg RN, James RB, Marier RL, Wood WH, Sanders CV, Kent JN. Microbiologic and antibiotic aspects of infections in the oral maxillofacial region. J Oral Surg 1979 Dec;37(12): 873-882.

16. Abubaker AO, Rollert MK. Postoperative antibiotic prophylaxis in mandibular fractures: a preliminary, randomized, double-blind and placebo-controlled clinical study. J Oral Maxillofac Surg 2001 Dec;59(12):1415-1419.

17. Hang, RH.; Assael, LA. Topazian's oral and maxillofacial infections. 4th ed. Philadelphia (PA): W.B Saunders; 2002. pp. 366-377.

18. Burke JF. Preventive antibiotic management in surgery. Ann Rev Med 1973 Feb;24:289-294.

19. Ruggles JE, Hann JR. Antibiotic prophylaxis in intraoral orthognathic surgery. J Oral Maxillofac Surg 1984 Dec;42(12): 797-801.

20. Longman LP, Martin MV. The use of antibiotics in the prevention of postoperative infection: A reappraisal. Br Dent J 1991 Apr;170(7):257-262.

21. Polk HC Jr, Simpson CJ, Simmons BP, Alexander JW. Guidelines for the prevention of surgical wound infection. Arch Surg 1983 Oct;118(10):1213-1217.

22. Wilkins J, Patzakis M. Choice and duration of antibiotics in open fractures. Orthop Clin North Am 1991 Jul;22(3):433-437.

23. Delinger EP, Ellis CS, Weaver LD, Wertz MJ, Droppert BM, Hoyt N, Brumback R, Burgess A, Poka A, Benirschke SK, et al. Duration of preventive antibiotic administration for open extremity fractures. Arch Surg 1988 Mar;123(3):333-339. 